\title{
A AFETIVIDADE E A AQUISIÇÃO DE UMA SEGUNDA LÍNGUA: \\ A TEORIA DE KRASHEN E A HIPÓTESE DO FILTRO AFETIVO:
}

\author{
Simone Francescon Cittolin - sfcittolin@unipar.br \\ (Professora de Língua Inglesa do CEFET, unidade de Medianeira e da UNIPAR - \\ Universidade Paranaense)
}

Resumo: O lado afetivo da aquisição de uma língua atrai a cada dia mais a atenção de pesquisadores. Resultados de pesquisas sobre a afetividade na aquisição de uma língua mostraram relações substanciais entre variáveis afetivas e proficiência. Variáveis afetivas como motivação, autoconfiança e ansiedade afetam a aquisição de uma segunda língua, tendo como efeito o aumento ou a diminuição da penetração de qualquer insumo compreensível que é recebido. Krashen acredita que professores podem fazer a diferença na motivação, nos níveis de ansiedade e na autoconfiança do alunos através de um ensino afetivo, mantendo assim o filtro afetivo baixo. $O$ ensino afetivo, então, representa a esperança de aperfeiçoar as atitudes, a motivação, a autoconfiança e os níveis de ansiedade, e conseqüentemente, o empenho tanto de alunos como de professores em fazer de uma aula boa, uma aula ainda melhor.

Palavras-chave: motivação, atitude, ansiedade, afeto, aquisição

O lado afetivo da aquisição de uma língua tem atraído a cada dia mais a atenção de pesquisadores nos últimos anos.(Hurd, 2002) Resultados de pesquisas com aprendizes universitários de línguas no final dos anos 90 sobre a afetividade na aquisição de uma língua mostraram relações substanciais entre variáveis afetivas e proficiência (Gardner, Tremblay e Masgoret, 1997) e destacaram o papel interdependente que a línguística, a cognição e o afeto têm na aquisição de uma segunda língua. (Yang, 1999) Essas pesquisas, na sua maioria, foram realizadas em contextos de sala de aula.

O afeto, como é definido pelos psicólogos, refere-se a emoções "e a uma variedade até mesmo mais ampla de fenômenos relacionados a emoções, estados de espírito, disposição e preferências". (Arnold, 1999)

Dulay, Burt e Krashen afirmam que o afeto de um indivíduo com relação a algo, uma ação ou uma situação em particular, se expressa através de como este algo, ação ou situação, preenche as suas necessidades e objetivos, e através dos efeitos resultantes nas suas emoções.

Dentre as investigações realizadas no campo da aquisição de L2 e LE que consideram o aluno, as suas diferenças individuais e a importância do domínio afetivo, o modelo de Stephen Krashen ocupa um lugar proeminente. Especialista no campo da linguística, sua 
reconhecida teoria de aquisição de segunda língua teve grande impacto em todas as áreas de pesquisa e ensino de segunda língua desde os anos 80.

Segundo o pesquisador, a força motriz para a aquisição de uma língua é a capacidade inata para adquirir línguas que todo ser humano dispõe e que governa e determina que forma possível uma linguagem humana pode tomar. A exposição à língua aciona o LAD, que é o Dispositivo para Aquisição de Línguas, e proporciona os detalhes da língua a serem aprendidos. Krashen (1987) formula sua teoria de aquisição composta por cinco hipóteses: a distinção entre aquisição e aprendizagem, a ordem natural, o monitor, o insumo e o filtro afetivo, sendo as duas últimas hipóteses consideradas por ele como causativas para que a aquisição ocorra.

No que tange à distinção entre aquisição e aprendizagem, o autor acredita que a aprendizagem é um processo consciente, é o saber a respeito de uma nova língua, é o conhecimento formal gramatical do sistema lingüístico. Para ele, este conhecimento por si só não garante a aquisição, o qual define como um processo subconsciente de assimilação natural, intuitivo, fruto de interações em situações reais de convívio humano em que o aprendiz participa como sujeito ativo, desenvolvendo habilidade prático-funcional sobre a língua. De acordo com Krashen, a aprendizagem é menos importante que a aquisição.

Schutz (2002) cita como um exemplo clássico de aquisição os indivíduos que residem no exterior durante um ano, atingindo um grau de fluência na língua estrangeira próximo do da língua mãe, porém, na maioria dos casos, sem nenhum conhecimento a respeito do idioma. Também cita como exemplo clássico de aprendizagem, os inúmeros graduados em letras, já habilitados, porém ainda com extrema dificuldade em se comunicar na língua que teoricamente poderiam ensinar.

A hipótese do monitor define a relação entre aquisição e aprendizagem. Os esforços espontâneos e criativos de comunicação decorrentes de nossa capacidade natural de assimilar línguas são policiados e disciplinados pelo conhecimento consciente das regras gramaticais dessa língua e suas exceções. Os efeitos desse monitoramento sobre pessoas com diferentes características de personalidade serão vários. Pessoas que tendem à introversão, à falta de autoconfiança, ou ao perfeccionismo, poderão desenvolver um bloqueio que compromete a espontaneidade devido à consciência da alta probabilidade de cometerem erros. Já as pessoas que tendem à extroversão, pouco se beneficiarão da aprendizagem, uma vez que a função de monitoramento é quase inoperante, pois está submetida a uma personalidade que se manifesta sem maior cautela.

Para Krashen (1987), professores deveriam almejar pessoas com um monitor ideal, que "usam o monitor quando é apropriado e quando este não interfere na comunicação." Eles não usam seu conhecimento consciente da gramática em conversações normais, porém o usarão ao escrever e planejar um discurso. Pessoas com um monitor ideal podem, portanto, usar sua competência aprendida como um suplemento para sua competência adquirida. 
A hipótese da ordem natural diz que a aquisição de estruturas gramaticais ocorre em uma ordem previsível. Algumas estruturas gramaticais tendem a ser adquiridas cedo, outras mais tarde, indiferentemente da língua nativa do falante. No entanto, isso não quer dizer, de acordo com Krashen, que a gramática deve ser adquirida nesta ordem natural de aquisição. Na verdade, Krashen rejeita seqüência gramatical quando o objetivo é aquisição de língua.

A hipótese do insumo, que é a amostra de linguagem oferecida ao aluno, é uma tentativa de Krashen de explicar como um aprendiz adquire uma segunda língua e, portanto, esta hipótese refere-se à aquisição e não à aprendizagem. De acordo com esta hipótese, o aprendiz progride numa ordem natural quando recebe insumo na segunda língua que está um pouco além do seu estágio atual de competência lingüística. Por exemplo, se um aprendiz está no estágio "i", então a aquisição ocorre quando ele é exposto a um insumo compreensível que pertence ao nível "i + 1". Esse insumo, além de compreensível, deve ser interessante, relevante, não seqüenciado gramaticalmente, oferecido em quantidade suficiente e em ambiente que incentive os alunos a sentir-se bem.

O pesquisador não acredita que apenas uma alta freqüência de exposição a certas estruturas fará com que as mesmas sejam adquiridas mais rapidamente. Segundo ele,

" o aluno só adquirirá o que estiver no ponto certo de seu desenvolvimento maturacional, não importando a freqüência com que ele é exposto, e nem o grau de dificuldade envolvido. Assim, as estruturas que esteja além de seu desenvolvimento serão apenas memorizadas, sem contudo, serem integradas, o que significa uma não capacidade desse aluno de usá-las efetivamente." (Krashen, 1987)

Para Krashen, o filtro afetivo é o primeiro obstáculo com que o insumo se depara antes de ser processado e internalizado. O filtro afetivo parte do processo interno no qual configuram os estados emocionais, as atitudes, as necessidades, a motivação do aprendiz ao aprender uma língua, e que regula e seleciona modelos de língua a serem aprendidos, a ordem de prioridade na aquisição e a velocidade nesta aquisição.

A hipótese do filtro afetivo, portanto, incorpora a visão de Krashen de que um número de variáveis afetivas tem um papel facilitador na aquisição de uma segunda língua. Estas variáveis afetivas incluem: motivação, autoconfiança e ansiedade. Aprendizes motivados, confiantes e com baixa ansiedade tendem a ser bem sucedidos no processo de aquisição de uma segunda língua. Esses aprendizes teriam um baixo filtro afetivo e absorveriam insumo com muito mais facilidade, enquanto que alunos tensos, ansiosos e com baixa estima, tenderiam a elevar o nível de seu filtro afetivo e a formar um tipo de bloqueio mental, diminuindo, assim, sua capacidade de absorção de insumo. Aqueles aprendizes cujas atitudes não são ideais com relação à aquisição de uma segunda língua, não apenas tenderão a procurar menos insumo como terão um alto filtro afetivo, e "mesmo que a mensagem seja entendida, impedirá que o insumo alcance a parte do cérebro responsável pela aquisição de língua, ou o LAD (Dispositivo de Aquisição de Língua)". (Krashen, 1987).

A motivação é uma das mais importantes dentre as variáveis afetivas, pois ela é a chave para a aprendizagem. Brown (1997) a encara, de uma maneira geral, como um impulso, 
uma emoção ou um desejo interno que direciona uma pessoa para uma determinada ação e, portanto, se percebemos um objetivo, e este objetivo é suficientemente atraente, ficaremos fortemente motivados a fazer o que for necessário para alcançá-lo.

Os principais estudos sobre motivação na aquisição de uma segunda língua emergiram dos interesses de Gardner, o qual apresenta distinção entre dois tipos de motivação: a motivação integrativa, expressa pelo interesse do aprendiz em aprender uma segunda língua por ter interesse pessoal e sincero nas pessoas e na cultura representadas pela outra língua; e a motivação instrumental, expressa pelo interesse do aprendiz em aprender uma segunda língua em função das vantagens práticas que se estabelecerão para aquele que a falar. Dulay, Burt e Krashen (1982) nos trazem um terceiro tipo de motivação: a identificação com o grupo social. Nesta, os alunos desejam não apenas uma participação social e cultural como na motivação integrativa, mas também desejam tornar-se membros do grupo da nova língua.

Pesquisas apontaram que aprendizes com motivação integrativa mais alta recebiam melhor as perguntas dos professores, respondiam voluntariamente à perguntas com mais freqüência, davam respostas mais corretas e também recebiam reforços mais positivamente. Porém, apesar da motivação integrativa ser considerada mais eficiente do que a instrumental, também se descobriu que em países onde se tem pouco contato com falantes nativos, mas onde a língua é necessária para negócios e objetivos profissionais, a motivação instrumental pode ser mais poderosa do que a integrativa.

Para Gardner, o comportamento do próprio professor pode influenciar positiva ou negativamente no desejo e na disposição do aprendiz para aprender e continuar aprendendo a língua. Outros pesquisadores também ressaltam a importância do papel do professor na motivação dos alunos e dizem que motivação é uma questão de atitude do professor. É de suma importância que professores inspirem seus alunos para aprender, pois acreditam que o que melhor motiva o aluno a aprender, continuar a aprender, perseverar e alcançar uma proficiência na língua alvo parece ser uma experiência positiva com o processo de ensino. Nessa perspectiva, a motivação deveria ser uma conseqüência em vez de uma causa do sucesso. E' imperativo, portanto, que professores descubram caminhos para motivar os alunos a agir de forma a alcançar seus objetivos, visto que esses são seres humanos com necessidades.

A motivação pode ter várias fontes. Uma delas pode estar no próprio ato de aprender e, nesse caso, o estímulo e a motivação seriam o interesse inato de aprender porque as situações de aprendizagem são atrativos por si só. Outra fonte ainda seria o próprio aluno que "traz" consigo motivação para a situação de aprendizagem e, finalmente, deve haver influências e incentivos externos, como por exemplo, do grupo social e da família.

Como Mary Finocchario sugere, a motivação é um sentimento fundamentalmente fomentado pelo professor na situação de aprendizagem. O momento da verdade, em que a motivação começa a ser realçada, ocorre quando o professor fecha a porta da sala, cumprimenta seus alunos com um sorriso acolhedor e caloroso, e passa a interagir com os alunos fazendo comentários ou perguntas que expressam interesses pessoais.

Outra variável da afetividade, a atitude, segundo Gardner (1990) está enraizada no contexto social e influencia a motivação que, por sua vez, influencia o desempenho em todos os contextos de aquisição. A atitude é, portanto, um componente essencial da motivação. É difícil medir e superar as variáveis do domínio afetivo, o que evidencia a intrincação entre elas. 
Uma atitude é um estado mental organizado através de experiências vividas pela pessoa que traz uma influência direta e dinâmica em sua resposta individual para todos os objetos e situações com as quais está relacionada. As atitudes do aluno em relação aos falantes da língua alvo, à língua alvo, ao professor, ao material didático e àmetodologia de ensino utilizados no curso, assim como à aprendizagem de línguas estrangeiras em geral, atuam de forma favorável ou desfavorável no processo de aprendizagem.

O professor, por sua vez, pode trabalhar para mudar as atitudes dos alunos, redirecionar expectativas e substanciar ou alterar os preconceitos desses em relação ao estudo da língua. Brown (1997) alerta os professores sobre a necessidade de estarem conscientes de que todos possuem atitudes positivas e negativas e que as atitudes negativas podem ser transformadas, freqüentemente, pela exposição à realidade, pois que geralmente emergem de estereótipos falsos.

Assim, a motivação do aluno para estudar uma língua será determinada por suas atitudes, prontidão para se identificar com a cultura-alvo e pela orientação para com o processo de aprender uma língua estrangeira.

Krashen (1987), MacIntyre e Gardner (1994), Aida (1994), Ehrman e Oxford (1995) e Horwitz $(1986,2000)$ destacam o papel da ansiedade como preponderante no processo de aprendizagem de línguas, e para a qual pesquisadores e educadores têm voltado cada vez mais a atenção como "um dos mais importantes fatores a prever sucesso na língua estrangeira." (Onwuegbuzie, Baley e Daley, 2000).

Na opinião de Jersil (1978), a ansiedade que afeta a educação pode ser definida como um estado de desordem e embaraço, uma espécie de perturbação, um sentimento difuso, indefinido, geralmente inconsciente que causa no indivíduo uma reação desproporcional à sua causa. Talvez a reação mais significativa seja a resistência que pode tomar várias formas, entre elas a recusa de aprender algo, não ouvir, não entender, não lembrar, não tentar, não aceitar.

Scovel (1978) distingue dois tipos de ansiedade relacionadas à aprendizagem de línguas: a ansiedade debilitante, que seria aquela que impede o aprendiz de ter um desempenho realmente de acordo com a sua capacidade, e a ansiedade facilitadora, que poderia ser vista como uma "energia positiva que motiva aprendizes" (Aida, 1994). Aprendizes com um elevado grau de proficiência e autoconfiança tendem a possuir um maior grau de ansiedade facilitadora, enquanto que aprendizes com baixo nível de proficiência e autoconfiança tendem a possuir um grau maior de ansiedade debilitante. Scovel ainda propõe existir a ansiedade como uma característica da pessoa, que se constituiria em um traço da personalidade do indivíduo e o estado ansioso, que se manifesta em determinados momentos em resposta a determinadas circunstâncias. A ansiedade que acomete os indivíduos em situações de aprendizagem de línguas seria uma combinação de ambas, ativada por situações, tais como participação em sala de aula, falar em público e exames em geral, atuando como causa, efeito ou ambas. 
Na tentativa de elaborar um conceito de Ansiedade de Língua Estrangeira (ALE), Elaine K. Horwitz, Jô Ann Cope Powell e Michael B. Horwitz partiram de um conceito geral de ansiedade como sentimento subjetivo de tensão, apreensão e preocupação associada à ativação do sistema nervoso, e propõe um conceito de Ansiedade de Língua Estrangeira que seria "um complexo de percepções, crenças, sentimentos e comportamentos relacionados ao contexto de sala de aula de língua estrangeira, ativados pela unicidade do processo de aprendizagem de uma segunda língua." (Nascente, 2000). Nesse complexo se destacariam três construtos que resumiriam os elementos acima mencionados: a apreensão de comunicação, a ansiedade de testes e o medo da avaliação negativa.

De acordo com MacCroskey (1984), apreensão de comunicação seria um nível de medo ou ansiedade de um indivíduo associada a situações reais de comunicação, ou perspectivas de situações de comunicação com um ou mais pessoas.

O segundo elemento da Ansiedade de Língua Estrangeira, a ansiedade de testes, é apresentado como uma tendência a considerar alarmantes as conseqüências de um desempenho inadequado ou não satisfatório numa situação de avaliação (Aida, 1994). Aida também aponta em sua pesquisa que a ansiedade de testes ocorre quando aprendizes que tiveram um desempenho insatisfatório no passado, desenvolvem pensamentos negativos durante as situações de avaliação, temendo o fracasso.

Por fim, o medo da avaliação negativa, segundo as investigações de Aida, é definido como apreensão, temor com relação à avaliação negativa de outros, isto é, de seus colegas e principalmente de seu professor.

Pesquisas realizadas por Nascente (2000) confirmaram o que a bibliografia especializada já propunha: que o construto do medo da avaliação negativa seria um dos fatores preponderantes na Ansiedade de Língua Estrangeira e que este é uma espécie de síntese dos outros dois construtos constituidores da ALE, a ansiedade de testes e a apreensão de comunicação.

Young (1991), em suas investigações, aponta que os três principais fatores geradores de ansiedade anteriormente citados são acompanhados de outros fatores, tais como ansiedades pessoais, crenças dos professores e dos alunos sobre como ensinar e aprender línguas, interação em sala de aula, procedimentos de ensino e experiências de aprendizagem anteriores.

A Ansiedade de Língua Estrangeira constitui um elemento dificultador de aprendizagem de língua estrangeira. No que se refere à superação da ALE, a conscientização, por parte de professores e de instituições de línguas, de que esse problema existe e que tem comprovadamente efeitos negativos tanto no processo quanto no produto da aprendizagem de língua estrangeira é fundamental para que se busquem estratégias para aliviar a tensão de sala de aula, tentando criar um ambiente de apoio e confiança que pode ajudar a reduzir os temores dos aprendizes frente aos seus colegas e professores. 
Krashen acredita que, para que o filtro afetivo seja mantido baixo, " os aprendizes não deveriam ser colocados na defensiva" e, portanto, professores podem fazer a diferença na motivação, nos níveis de ansiedade e na autoconfiança do alunos, através de um ensino afetivo que pode variar do tradicional e das metodologias centradas no aluno à estratégias de orientação humanística. Charles Curran defende um conceito unificado de homem, e diz que fatores físicos, intelectuais, psicológicos e emocionais influenciam na aquisição de uma língua. Afeto e uma relação amigável entre professor e aluno proporcionam a estrutura necessária na qual o professor tem um papel não-autoritário e não-diretivo, e as atividades são centradas no aluno.

O ensino afetivo, então, representa a esperança de aperfeiçoar as atitudes, a motivação, a autoconfiança e os níveis de ansiedade, e conseqüentemente, o empenho tanto de alunos como de professores em fazer de uma aula boa, uma aula ainda melhor.

"The best methods are therefore those that supply comprehensible input in low anxiety situations, containing messages that students really want to hear. These methods do not force early production in the second language, but allow students to produce when they are "ready", recognizing that improvement comes from supplying communicative and comprehensible input, and not from forcing and correcting production. "(Stephen Krashen)

\section{REFERÊNCIAS BIBLIOGRÁFICAS}

Arnold, J. (ed.) (1999). Affect in language learning. Cambridge: Cambridge University Press.

Brown, H. D. 1997. Cognitive and affective characteristics of good language learners. In: C. A. Henning (ed.), Proceedings of the Los Angeles Second Language Research Forum. Los Angeles. UCLA, Departament of English, TESL.

Dulay, H., Burt, M., \& Krashen, S. (1982). Language two. Oxford: Oxford University Press.

Ehrman, M., \& Oxford, R. (1995). Cognition plus: Creatles of language learning success. Modern Language Journal, 76, 67-89.

Gardner, R. (1990). Attitudes, motivation, and personality as predictors of success in foreign language learning. In T. Parry \& C. Stansfield (Eds.), Language aptitude reconsidered (pp. 179221) Englewood Cliffs, NJ: Prentice-Hall.

Gardner, R., P. Tremblay and A.M. Masgoret (1997) Towards a full model of second language learning: an empirical investigation. The Modern Language Journal, 81: 344-362

Hurd, S. (2000) Distance Language Learners and learner support: beliefs, difficulties and use of 
strategies. Links and Letters 7: Autonomy in L2 Learning: 61-80.

Hurd, S. (2002) Taking account of affective learner differences in the planning and delivering of language courses for open, distance and independent learning. Subject Center 2002 Conference Proceedings: Open University.

Krashen, Stephen D.( 1987) Principles and Practice in Second Language Acquisition. PrenticeHall International.

Krashen, Stephen D. (1988) Second Language Acquisition and Second Language Learning. Prentice-Hall International.

Masgoret, A.M. \& Gardner, R.C. (2003) Attitudes, motivation and second language learning: meta-analyses of studies by Gardner and associates. In D-myei, Z. (Ed.) Attitudes, orientations and motivations in language learning (The Best of Lanbguage Learning Series). Oxford: Blackwell.

Onwuegbuzie, A., Bailey, P., \& Daley, C. (1999). Factors associated with foreign language anxiety. Applied Psycholingustics, 20, 217-239.

Schütz, Ricardo. "Stephen Krashen's Theory of Second Language acquisition." English Made in Brazil <http://www.sk.com.br/sk-krash.html>. Online. 30 de janeiro de 2002.

Schütz, Ricardo. "A Psycholinguistic Teaching Approach." English Made in Brazil $<$ http://www.sk.com.br/sk-krash.html>.

Schütz, Ricardo. "Language Learning - Language Acquisition" English Made in Brazil <http://www.sk.com.br/sk-krash.html>. Online. 12 de junho de 2002.

Yang, N-D (1999) The relationship between EFL learners beliefs and learning strategy use. System 27: $515-535$. 